\title{
Translating paste backfill admixture results from the laboratory into the field
}

\author{
Fabian Erismann Sika Services, Switzerland \\ Christophe Kurz Sika Technology, Switzerland \\ Martin Hansson Sika Sweden, Sweden \\ John Almas Sika China, China
}

\begin{abstract}
Paste backfill admixtures have been used in mine paste backfill plants for many years. Their use has been targeted to improve specific properties of the paste such as the water and binder requirements for a certain workability and strength, to improve the slump and flow characteristics, to reduce paste line pressures or to enhance the stability of the paste in order to reduce risk of line blockages.

The economic justification for the use of paste backfill admixtures was in earlier days questioned in projects across the world as visible operational cost improvements could not always be clearly demonstrated. With the development of new generation paste backfill admixtures over the past years, the economic benefits can now be clearly demonstrated. State of the art admixtures can impact the economics of paste plants and associated infrastructures significantly. Sika together with its partners utilised lessons learned from concrete admixtures and translated this knowledge in order to apply the same $p$

rinciples in paste plants across the globe. Significant cement reduction targets of up to 50\% could be reached, which changed the perception towards the use of admixtures significantly. Translating initial laboratory results into the field remains one of the key challenges. This paper will outline this critical transition from laboratory into the field using three case studies from mines located in Europe and Africa. The results obtained in the laboratory can often be translated into the real world with minor variances of the critical parameters such as the admixture dosage, slump and strength development but we also show that there are exceptions. Understanding the actual origin and composition of the paste remains critical for the selection of the best performing paste backfill admixture and for a successful transition from promising laboratory results into the field.
\end{abstract}

\section{Introduction}

Utilizing dewatered tailings for underground backfilling is becoming the standard in many underground cut and fill and long hole stoping operations globally. At the same time, increased cement consumption and rising operating costs represent a major issue in many mines. Optimizing the cost performance of the backfilled mix as well as the reliability of the backfill plant has become a major objective in recent years. The introduction of admixtures into the paste backfill mix has been successful in several mining operations. The selection of the right admixture and the implementation of the admixture into the daily operation are critical to fully utilize the potential of admixtures and to materialize the targeted cost savings. The first step for evaluating admixtures for a given paste plant is successful laboratory trial with the tailings and binder in use. 
Once laboratory trials have been successfully completed, the system needs to be proven reliable in large scale, via on site field trials at the paste plant. This transition from the laboratory into the field is critical.

Based on three case studies we will outline this transition methodology. The three case studies cover completely different ore deposits from where the wetted-out tails were sourced, mixed with binder and admixture and backfilled into underground stopes. Remaining within the workability limits as well as reaching the required strength values after a given time are the defining parameters that had to be fulfilled and within this range, the mix design was cost-optimized.

\section{Admixture selection process}

Selecting effective admixtures for each paste was the first and most important step in the cost optimization process. The precondition for a successful selection process is a good and detailed understanding of the tailings and the binder composition. The geochemical characteristic of the tailings, by far the largest component of the paste mix by volume, has a dominating effect on the effectiveness of a chosen admixture (Erismann et al., 2016). Understanding the geological origin of the ore deposit and hence the tailing mineralogical composition and sieve curve is critical. Over the past years, Sika developed an extensive database from tailings across the globe, covering most deposit types that are today mined with selective underground methods that normally utilize cemented paste backfilling. This database is the foundation of how we approach backfill plants and provides very useful selection criteria in order to streamline this critical selection process. Once the right admixture has been identified and the best cost performing dosage has been determined in the laboratory, the next step is to prove the upgraded paste mix design in the field.

\section{$3 \quad$ Laboratory trials}

Laboratory trials were set up in a way to be easily reproducible in the paste laboratory at the mine site with minimal equipment needs. Standard Hobart concrete mixers as well as casted mortar bars were used to test different mix designs including compressive strength testing. Transparent cylinders are used for bleeding tests. Workability of the paste is tested by using half sized concrete Abrams cones. Compressive strength testing takes place according to the mines requirement but usually after 7 and 28 days and sometimes also after 56 days. Promising admixtures usually lead to strong increase in slump and slump-flow of the paste mix at moderate dosages (Erismann et al., 2016). Such a slump increase of the reference mix is usually a precondition to upgrade the paste mix design by reducing the water content of the paste. Once the best cost performing admixture has been identified, the water content is reduced by such extent that the workability limits of the paste (required slump) are maintained. Once the upgraded compressive strength results have been obtained, the binder is reduced to such extent that the overall compressive strength requirement is within the accepted boundaries.

\section{$4 \quad$ Onsite trials}

Once the optimized mix design has been identified, the new system needs to be tested on a large scale in order to verify the cost savings under real conditions. The shear energy as well as the scale of materials mixed is obviously much different when comparing laboratory trials to field trials. However, the approach at the paste plant is very much the same as in the laboratory. The admixture is dosed directly into the wetted-out mix using standard dosing equipment as seen in Figure 1. The admixture is dosed into the paste hopper or directly into the paste mixer. In order to prevent an overdosing of the system, the starting dosage is around $50 \%$ of the actual dosage determined in the laboratory. Once this dosage has been added for a few cycles (in batched paste plants) or for a certain time interval (for continuous paste plants) the dosage can be step-wise 
increased until the targeted dosage from the laboratory trials has been reached. Standard paste cylinders are filled with the different paste mixes and stored under controlled conditions for compressive strength testing.

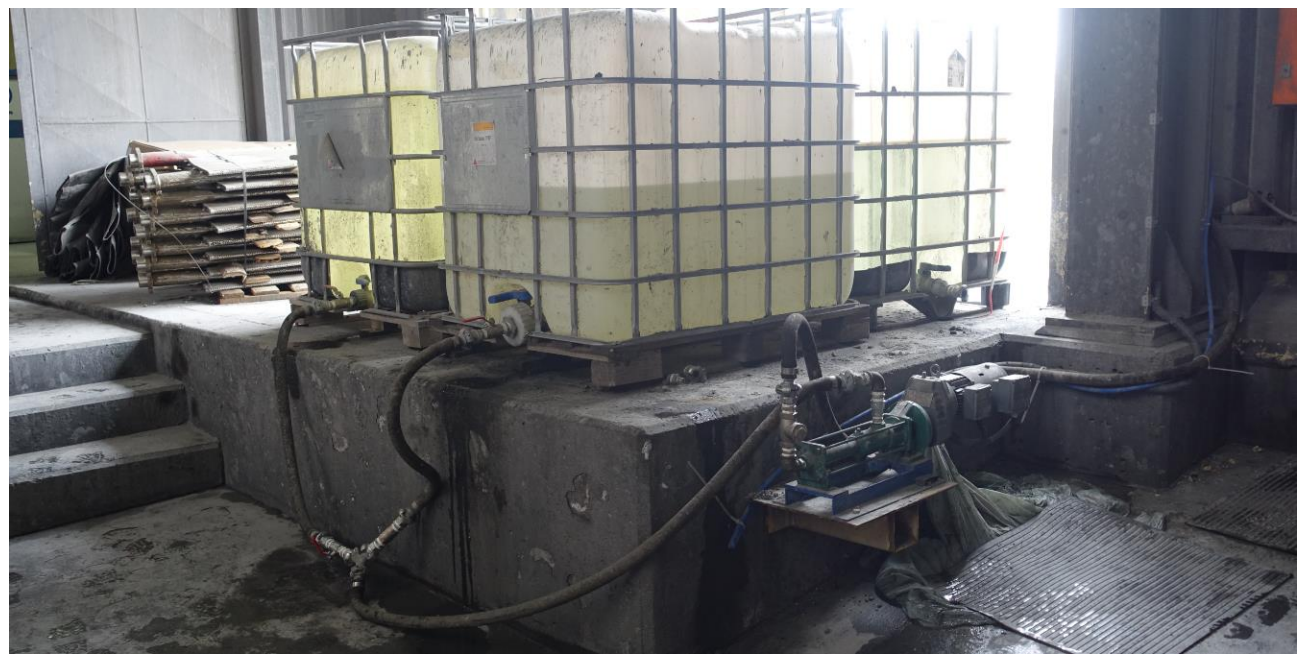

Figure 1 Admixture set-up at the paste plant. Bulk containers are coupled to the dosing unit (right side of image) that is coupled to the control system of the paste plant. The admixture is then pumped to the dosing point

\section{$5 \quad$ The case studies}

The following three case studies have been selected to illustrate the successful transition from the laboratory to the paste plant.

- Polymetallic zinc-lead-copper SEDEX deposit in Northern Europe.

- Polymetallic, epithermal gold-copper deposit in Eastern Europe.

- Orogenic gold deposit in West Africa.

These three deposits have a completely different origin, deformation and alteration history and hence can be seen as completely independent geological systems. These differences become clear when looking at the alteration mineralogy of the deposit, the metallurgical composition as well as the grind size needed in order to liberate the minerals of interest. All of these parameters have a defining impact on how the admixtures will interact with the tailings derived from these three deposits. As a result of these differences, different binders were used in varying quantities in order to obtain the required compressive strengths. These case studies and the requirements of the paste backfill operation are described briefly below.

\subsection{Polymetallic zinc-lead-copper SEDEX deposit in Northern Europe}

This deposit is a SEDEX type deposit or a "sedimentary exhalative deposit" which are widely known on the globe. Other well-known deposits of similar type are the Red Dog (Moore et al., 1986) deposit in Alaska, Lady Loretta and HYC deposit in Australia (Robb, 2005). SEDEX deposits represent a major source for zinc, lead and other base metals. This particular deposit is rich in quartz due to a distinct silica alteration phase present in the deposit. Furthermore phyllosilicates such as micas and chlorite with biotite being the dominant phyllosilicate phase as well as more mafic composites such as pyroxenes together with abundant pyrite complete the mineralogical picture. Clay minerals are absent however there are traces of metamorphic talc as well as more than $1 \%$ dolomite in the tailings composite. The light grey color (Figure 2 ) of the paste is an indication of the low total iron sulfide content (less than $2 \%$ of total tailing mass).

Cut and fill is the main mining method and the paste plant has a nominal backfill capacity of around 1,500 tons per day. The wetted-out tails have a solid content of $75 \sim 80 \%$. Primary plug fill designs are usually done 
using $8 \sim 10 \%$ binder to maintain a 28 day compressive strengths of $1 \mathrm{MPa}$. For the remaining fill, the cement consumption is reduced to $4 \%$ to maintain strength of around $0.4 \mathrm{MPa}$ after 28 days. Large, solid piston pumps are used to pump the paste down into the underground infrastructure.
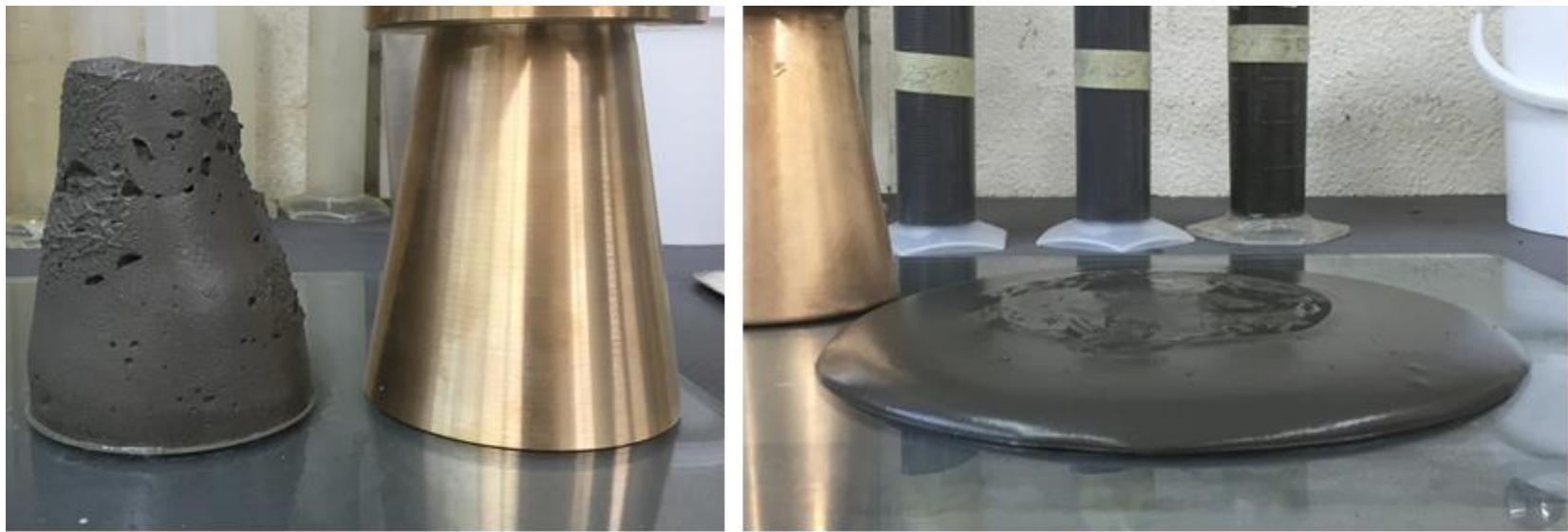

Figure 2 Laboratory results with the Sika Stabilizer-303 MBF. Left image the reference mix without admixture, right image after the addition of $1.5 \%$ admixture by weight of cement

Laboratory trials have shown that a reference mix of around $8 \%$ binder is resulting in a 28 day compressive strength of around $1 \mathrm{Mpa}$. This correlates well to what is actually achieved in the placed fill and the current mine paste mix design. The Sika Stabilizer-303 MBF is a polymer based paste admixture that was especially designed for polymetallic VMS and SEDEX deposits and had a very positive effect on this paste. In Figure 2 the strong plasticizing effect is visualized, using a moderate $1.5 \%$ dosage on the paste mix containing $8 \%$ binder. In a next step the water was reduced to achieve the slump requirement from the paste plant. Compressive strength results in Figure 3 show that the upgraded mix design contains less water and achieves the $1 \mathrm{MPa}$ strength with a binder content of around $5 \%$. The admixture volume was kept constant.

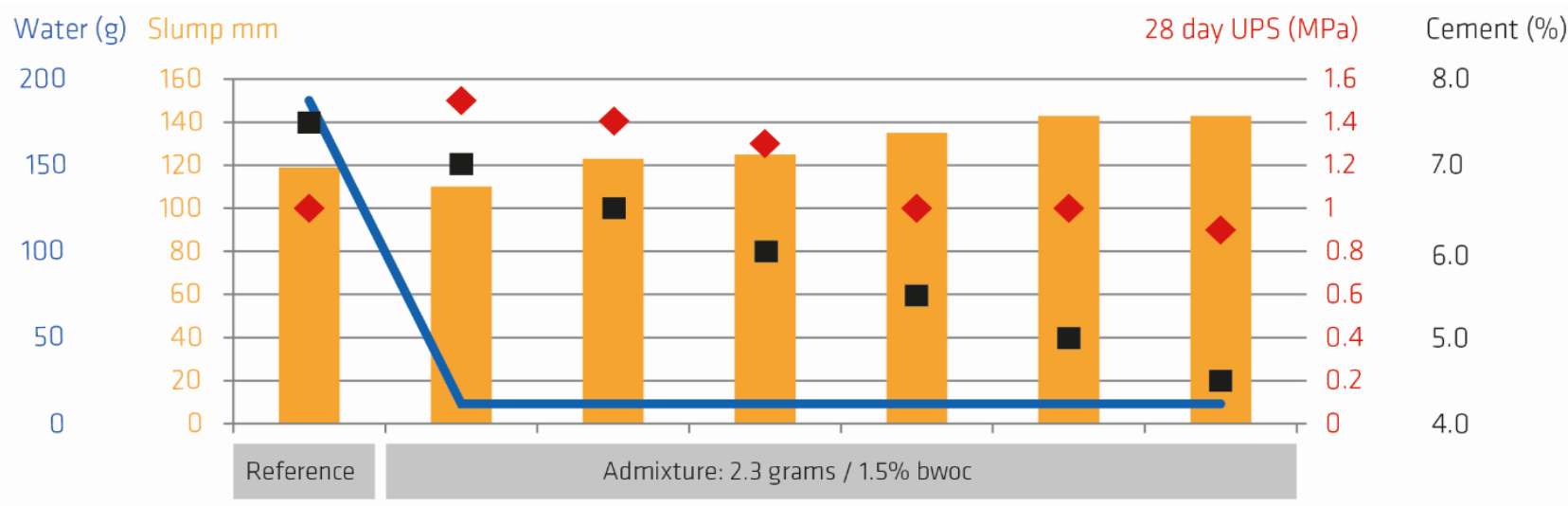

Figure 3 Laboratory results from the SEDEX paste trials at 28 days. The adjusted mix design was estimated to contain around $5 \%$ cement which is around $30 \%$ below the reference mix. Also note the slight increase in slump which indicates that the optimization process is not optimized yet and water can be reduced further

On the basis of good laboratory results, the client opted to commence full scale field trials immediately. The admixture dosing system was installed at the batched paste plant and the admixture was dosed over extended period of time at different dosages. Water addition was controlled manually. The admixture starting dosage was chosen to be $1 \%$ by weight of cement and the paste initially had a binder composition of $8 \%$. This dosage resulted in a strong segregation of the paste and was immediately reduced to lower levels to get back to the required slump values. Based on continued slump testing and evaluating compressive strength results an optimal admixture dosage was determined at around $0.42 \%$ (bwoc) and the upgraded mix 
design contains $25 \%$ less cement. The reference mix resulted in a compressive strength of around $0.8 \mathrm{MPa}$ as did the updated mix-design as shown in Figure 4. In addition to the lower admixture dosage that was needed at full scale, the overall results correlated well with the results obtained in the laboratory. Other positive side effects of the admixture addition was a $30 \sim 40 \%$ reduction in paste line pressures, an increase in the solid content as well as cutting the release time of the mixer by $50 \%$ in order to achieve the accepted energy draw level to release the paste into the hopper.

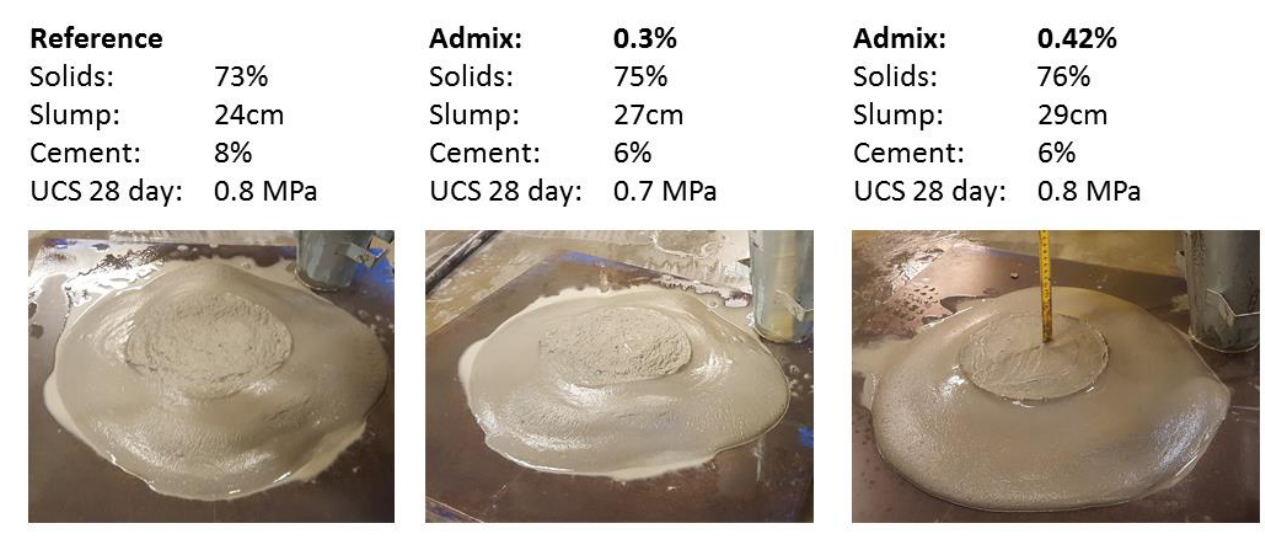

Figure 4 On site slump results for the different mix designs and admixture dosages. The goal was to keep the slump constant and adjust the slump increase effect of the admixture by manually reducing the water to the paste mix

\subsection{Polymetallic, epithermal gold-copper deposit in Eastern Europe}

This deposit in Eastern Europe is an epithermal gold-copper deposit with a generally complex metallurgy and mineralogical alteration pattern that has a strong effect on the paste and the tested admixtures. Complex mineralogical compositions are common for epithermal systems (Arribas et al., 1995). Such deposits include the Porgera Mine in PNG, The Escobal deposit in Guatemala and many of the largest silver-gold deposits in Turkey, Mexico and Peru. Due to the partly refractory nature of the ore, the tails have a fine grind, whereas 40\% are below 20 microns in size. The tailings include a large amount of quartz due to the pervasive silica overprint of the deposit. Sericite is very common as is chlorite. Large amounts of clay minerals are present, mainly kaolinite most likely originating from the argillic alteration envelope. The paste plant has a daily capacity of around 4,000 tons of paste. The target compressive strength values for the $30 \mathrm{~m}$ high long hole stope filling is $0.45 \mathrm{MPa}$ after 28 days. Currently, this strength value is reached using $6 \%$ binder. Initial laboratory results showed large slump increase of the paste with the Sika Stabilizer ${ }^{\oplus}-310 \mathrm{MBF}$ as shown in Figure 5.
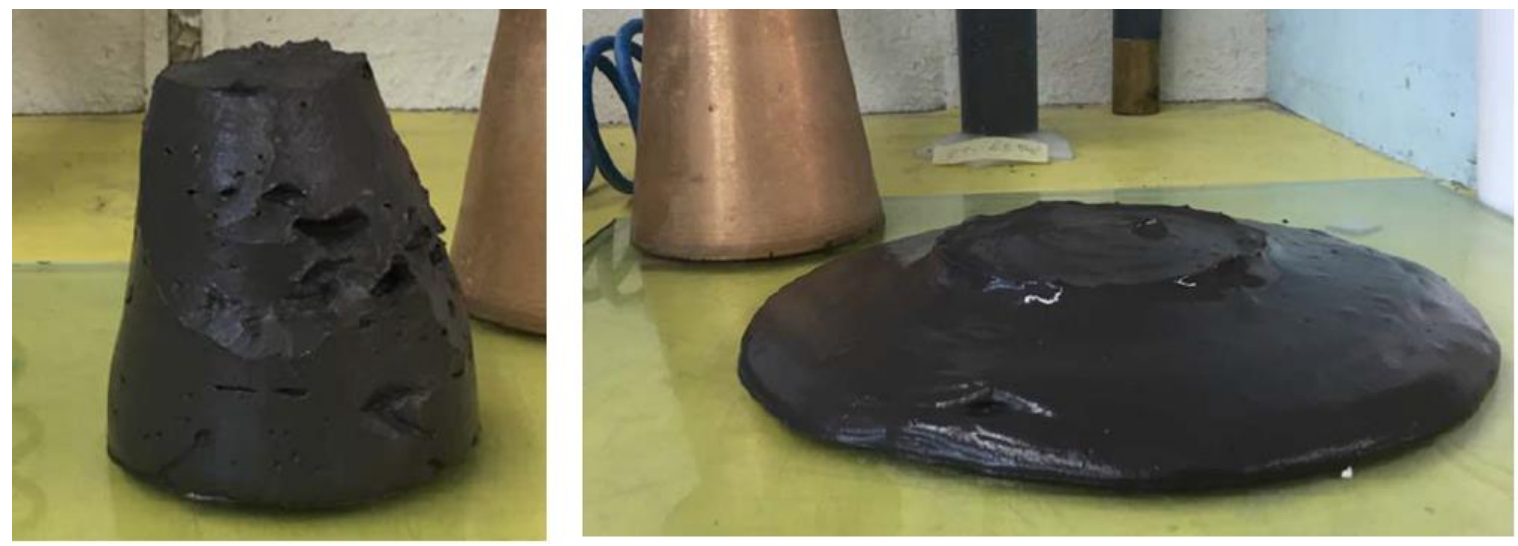

Figure 5 Laboratory results with the Sika Stabilizer ${ }^{\circledR}-310$ MBF. Left image: the reference mix without admixture, right image: the paste mix containing $1.5 \%$ admixture (bwoc) 


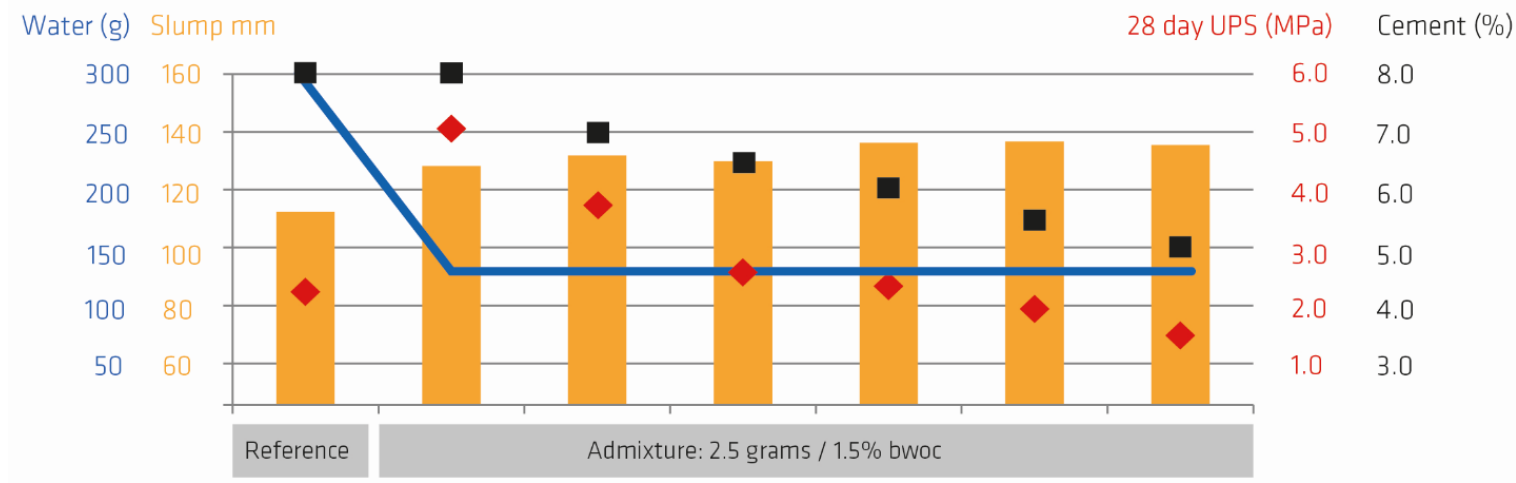

Figure 6 Laboratory results from the epithermal paste trials. The $\mathbf{2 8}$ day strength of the reference mix with $8 \%$ binder was achieved with around 6\% binder by the use of Sika Stabilizer ${ }^{\circledR}-310$ MBF. Also note the slight increase in slump which indicates further water reducing potential

Laboratory results indicated that a reference mix design (in this case with $8 \%$ cement content, Figure 6 ) could be optimized to $6 \%$ by maintaining compressive strength levels which were much higher in the laboratory than what could be achieved in the field. Based on these results, the client decided to go for full scale trials using a reference mix with $6 \%$ binder as a reference. During the site trial, the dosage was increased to $1.5 \%$ admixture by weight of $6 \%$ cement in the mix. Solids content increased immediately from 72 to $75.5 \%$ by maintaining the slump as shown in Figure 7. Accordingly, the 28 day compressive strength value increased from 0.49 to $0.72 \mathrm{MPa}$, which is an increase of $47 \%$. During further trials the updated reference mix contained $27 \%$ less binder by maintaining the required $0.45 \mathrm{MPa}$ strength level.

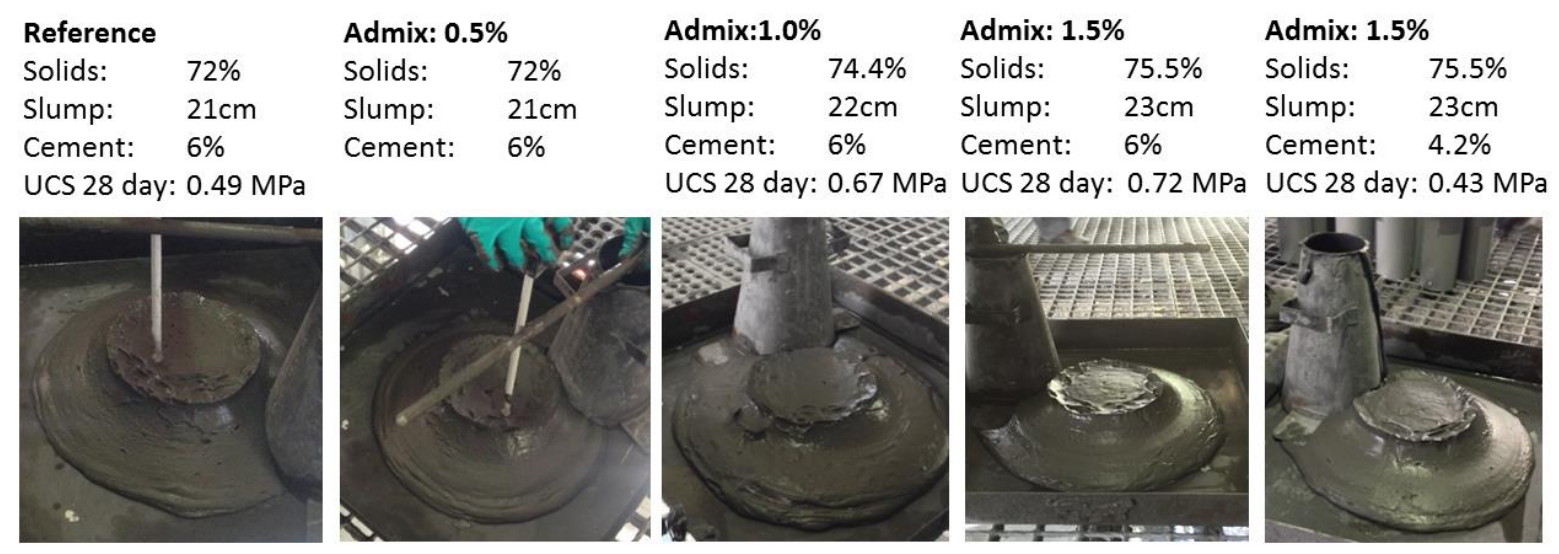

Figure 7 On site slump results for different admixture dosages. Not the increase in solids from the reference to the samples with $1.5 \%$ admixture and the increase in strength at constant binder content

\subsection{Orogenic gold deposit, West Africa}

This gold deposit in West Africa is a typical Birimian hosted, orogenic quartz lode deposit. The mineralogy is typical for these deposits and dominated by quartz, iron oxides and carbonaceous material to a lesser extent. Orogenic gold deposits represent a major source of gold and can be found in many locations, mainly in cratons such as the Abitibi belt in the Canadian shield, the Birimian in West Africa and the Yilgarn in Western Australia that hosts orogenic deposits such as Red Lake (Dubé et al., 2004), Obuasi (Yao et al., 2000) and Granny Smith (Ojala et al., 1993).

The paste from this long-hole stoping operation originally had a solid content of $80 \%$ and a required slump of $20 \sim 22 \mathrm{~cm}$. Binder content varies depending on the 28 day strength requirement, which is $1.5 \mathrm{MPa}$ at around $9 \%$ binder dosage for the primary plug fillings and for the remaining pours a binder content of around $5 \%$ is used for a required compressive strength of $0.5 \mathrm{MPa}$.

Initial laboratory results showed that by using $2 \%$ of Sika ${ }^{\circledR}$ Stabilizer-305 MBF (by weight of cement), it was 
possible to strongly increase the slump of the reference paste as shown in Figure 8. Based on this admixture dosage, water was reduced from the reference mix and samples were tested with different cement contents. The compressive strength results were encouraging, showing a strong increase of 28 day strength results when upgrading the mix design in combination with the admixtures.
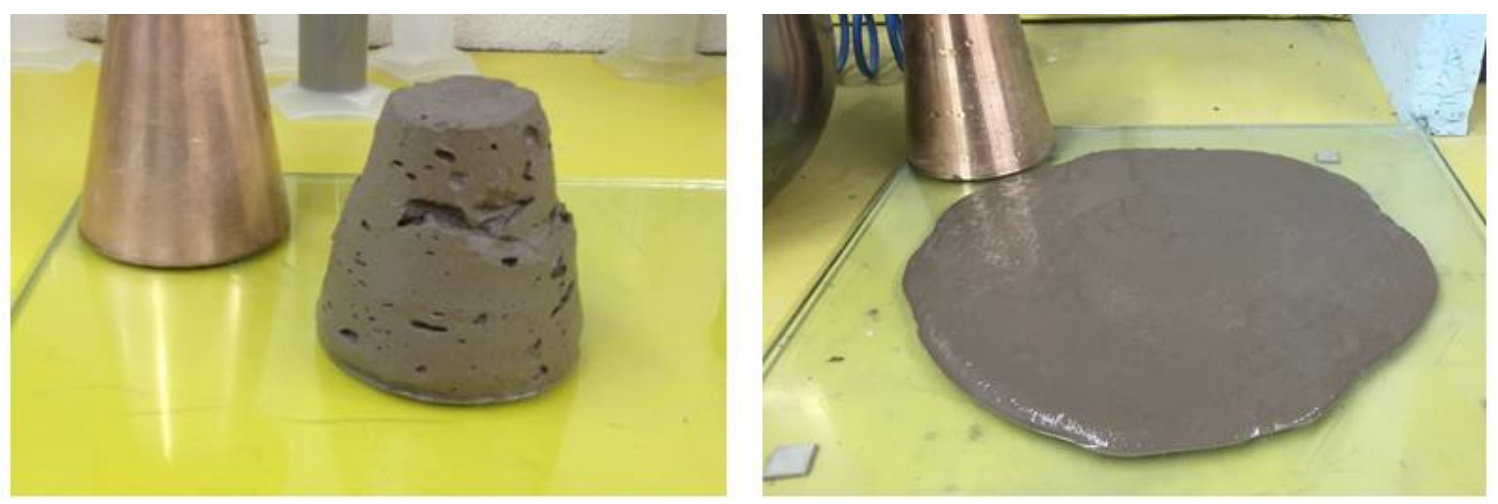

Figure 8 Laboratory results with the Sika Stabilizer-305 MBF. At a 2\% admixture dosage, the slump of the reference mix increases strongly (right image) compared to the reference mix without admixture (left image)

With the addition of admixtures, the solids content in the paste mix increased from 81 to $84 \%$ whilst maintaining the slump and hence workability of the paste. Figure 9 summarizes the laboratory results. Based on the laboratory results a reduction from $7 \%$ binder down to $4.5 \%$ seemed possible to maintain the strength of the reference mix. Based on the laboratory results and the potential to decrease cement consumption significantly, it was decided to go for full scale trials and implementing an admixture dosing system at the paste plant.

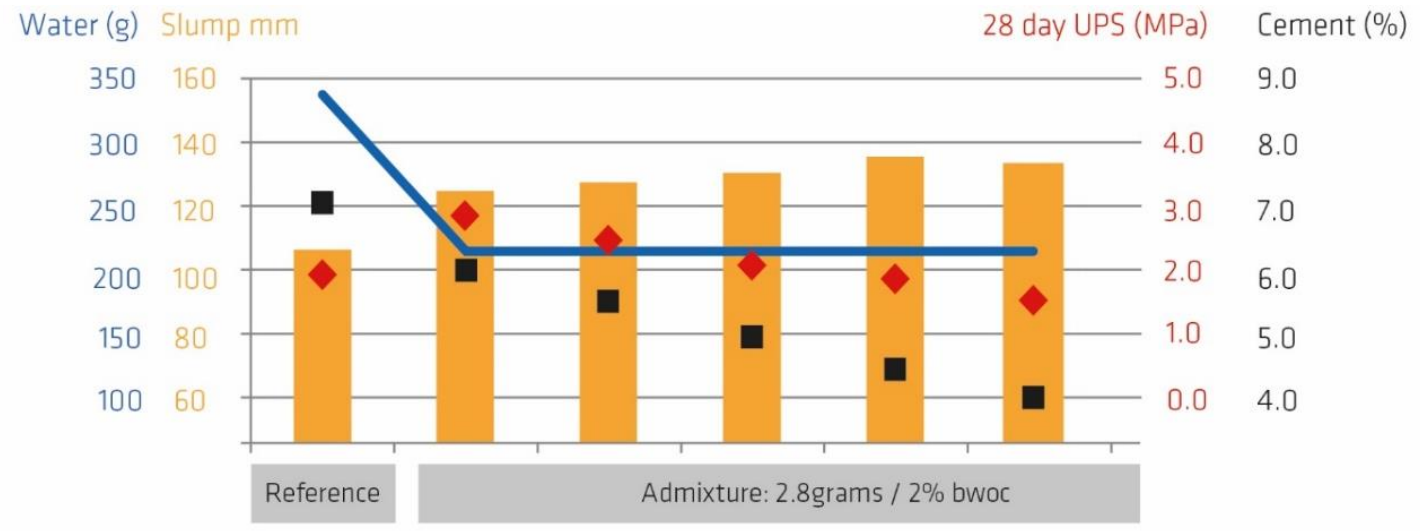

Figure 9 Laboratory results from the orogenic paste trials. Note the strength increase from the reference at $6 \%$ binder to the sample with admixtures and same binder content

During the trial period, the paste plant was running full scale fill cycles using different cement contents. The admixture dosage was adjusted in order to maximize water reduction in the paste mixer while maintaining within the required slump limits. An admixture dosage of $1.5 \%$ by weight of cement over the whole trial period proved to be efficient to achieve good water reduction and hence increase in solid content and compressive strength. For the $1.5 \mathrm{MPa}$ strength requirement after 28 days, the cement consumption could be reduced from 10 to around $7 \%$, a reduction of $30 \%$ and consistent with the cement reduction achieved in the laboratory. 


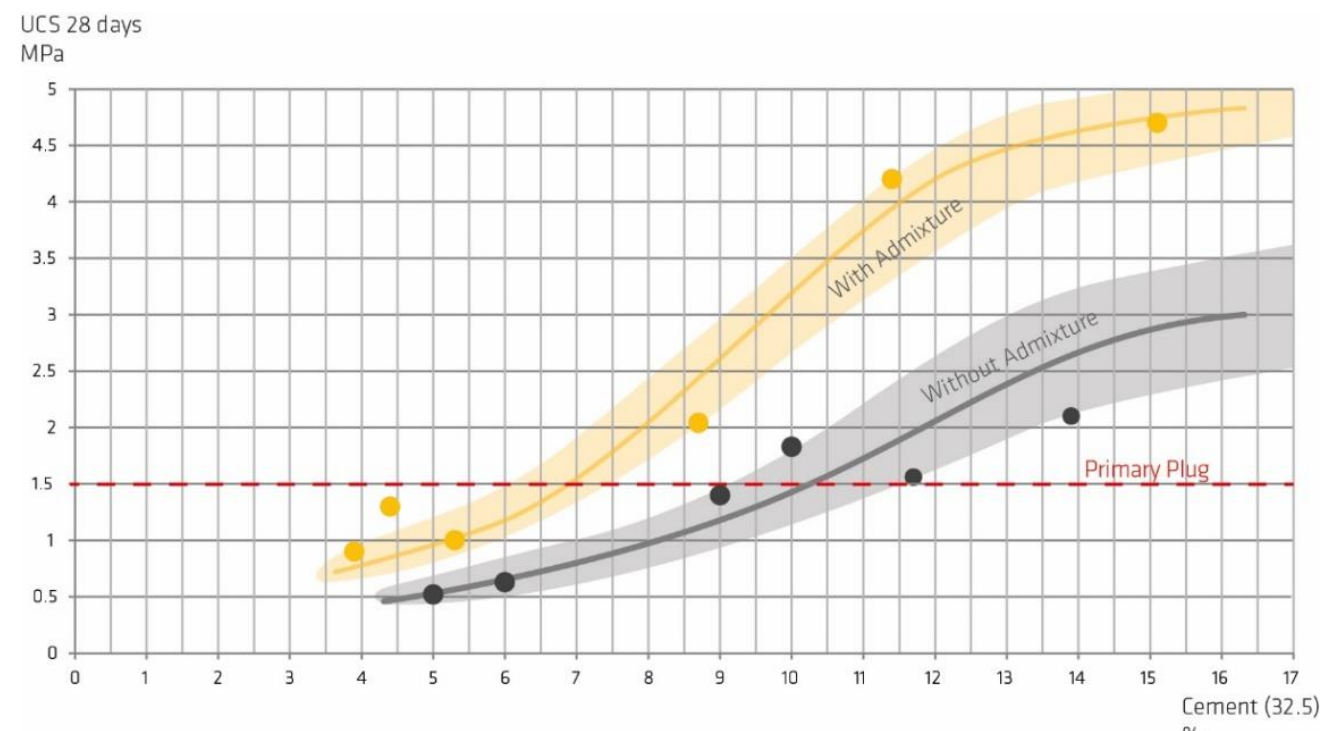

Figure 10 Large scale trial results for different cement contents. Note the significant increase in strength for a given cement content when adding admixtures at an average dosage of $1.5 \%$ by weight of cement

\section{Conclusion}

Laboratory and on site mine trials have shown that results in the laboratory can be translated into the field. The admixture dosage level as well as the improvement in strength determined in the laboratory, correlates relatively well with field performance. However, strength results in the laboratory often exceed site performance for a given cement content, although at a generally lower needed admixture dosage. Therefore, the increase in strength on a percentage basis needs to be seen as a guidance of what is actually possible in the field. In one of the described cases, the admixture dosage was materially lower than what was determined in the laboratory. The reason for this is somewhat unknown but is likely linked to differences in mixing energy, the effectiveness of the dispersing effect of the admixture and the design of the paste mixer. The same case also emphasized the importance not to overdose the paste system with admixtures in order to prevent segregation of the paste mix and to avoid line blockages in the very beginning of admixture trials. Starting with a low admixture dosage in the beginning and then slowly increasing the dosage to the planned level is therefore highly recommended. Understanding the mineralogy of the tailings is critical for the selection process of the best suited admixture. Using this knowledge, cement reductions of $30 \sim 40 \%$ is well within the achievable limit in combination with a moderate admixture dosage of $1 \sim 2 \%$ by weight of cement. Only effective admixtures will be able to improve the overall cost performance of the paste plant and result in material cost savings especially in regions where cement prices are high. Reducing the cement content remains the foremost driver for the use of paste backfill admixtures, if this is not possible, the justification of using admixtures remains limited. There are no shortcuts but to properly assess the behavior of the paste with a given admixture in order to achieve a successful outcome.

\section{References}

Arribas, A., Hedenquist, J.W., Itaya, T., Okada, T. Concecion, R.A. and Garcia, J.S. 1995, 'Contemporaneous formation of adjacent porphyry and epithermal Cu-Au deposits over 300 ka in northern Luzon, Philippines'. Geology, vol. 23, pp. 337-40.

Dubé, B., Williamson, K., Mcnicoll, V. 2004, 'Timing of Gold Mineralization at red Lake, Northwestern Ontario, Canada: New Constraints from U-Pb Geochronology at the Goldcorp High-Grade Zone, Red Lake Mine and the Madsen Mine', Economic Geology.

Erismann, F., Hansson M., Kurz, Ch., O'Hara, S. 2016, 'The Benefits of Incorporating Admixtures into Mine Paste Backfill', Proceedings of the 19th International Seminar on Paste and Thickened Tailings, Gecamin, Santiago. 
Moore, D.W., Young, L.E., Modene, J.S., Plahuta, J.T. 1986, 'Geologic setting and genesis of the Red Dog zinc-lead-silver deposit, Western Brooks range, Alaska'. Economic Geology, pp, 1696-727.

Ojala, J., Ridley J.R., Groves D.I., Hall G.C. 2003, 'The Granny Smith gold deposit: the role of heterogeneous stress distribution at an irregular granitoid contact in a greenschist facies terrane', Mineralium Deposita vol.28 no. 6, pp. 409-419.

Robb, L.J. 2005, Introduction to ore forming processes.

Yao, J., Robb L.J. 2000, 'Gold mineralization in Palaeoproterozoic granitoids at Obuasi, Ashanti region, Ghana:Ore geology, geochemistry and fluid characteristics'. South African Journal of geology, vol. 103, pp. 255-278. 